\title{
PENGARUH PORSI KEPEMILIKAN PUBLIK, PROPORSI DEWAN KOMISARIS INDEPENDEN, DAN UKURAN KAP TERHADAP PENGUNGKAPAN SUKARELA
} (Studi Empiris Pada Perusahaan Property Dan Real Estate Yang Terdaftar Di Bursa Efek Indonesia Tahun 2014-2016)

\author{
Herlina Endah Agustin*), Rakhmawati Oktavianna \\ Universitas Pamulang \\ Email : Helina3008@gmail.com ; r.oktavianna21@gmail.com
}

\begin{abstract}
Investors and users of financial information need voluntary disclosure to make better decisions in the future because mandatory disclosures alone are still not enough. In this study, choosing the portion of public ownership, the proportion of independent commissioners and KAP size as factors that influence voluntary disclosure. By using purposive sampling, it was obtained a study sample of 27 property companies and real estate listed on the Indonesia Stock Exchange, the period 2014 to 2016. The results of multiple regression analysis indicate that the portion of public ownership and KAP size has a significant effect on voluntary disclosure, while the proportion of board of commissioners has no significant effect on voluntary disclosure.
\end{abstract}

Keywords: Influence of Public Ownership Portion, Voluntary Disclosure, Proportion of Independent Board of Commissioners, KAP Size

\begin{abstract}
Abstrak
Investor dan pengguna informasi keuangan membutuhkan pengungkapan sukarela untuk membuat keputusan yang lebih baik dimasa depan karena pengungkapan wajib saja masih tidak cukup. Dalam penelitian ini, memilih porsi kepemilikan publik, proporsi komisaris independen dan ukuran KAP sebagai faktor-faktor yang mempengaruhi pengungkapan sukarela . Dengan menggunakan purposive sampling, didapatkan sampel penelitian sebanyak 27 perusahaan properti dan real estaste yang terdaftar di Bursa Efek Indonesia, periode tahun 2014 sampai dengan tahun 2016. Hasil dari analisis regresi berganda menunjukkan bahwa porsi kepemilikan publik dan ukuran KAP berpengaruh signifikan terhadap pengungkapan sukarela, sedangkan proporsi dewan komisaris tidak berpengaruh signifikan terhadap pengungkapan sukarela.
\end{abstract}

Kata Kunci : Pengaruh Porsi Kepemilikan Publik,Pengungkapan Sukarela, ProporsiDewan Komisaris Independen, Ukuran KAP 
Vol.2, No. 1, Jan. 2019

\section{PENDAHULUAN}

Penyajian laporan keuangan tidak terlepas dengan pengungkapan porsi kepemilikan masyarakat, hal ini karena masyarakat ingin mengetahui seberapa jauh perkembangan perusahaan tersebut. Menurut Ainun dan Fuad (2000) dalam Prijanto (2012) adanya perbedaan jumlah saham yang dimiliki oleh investor dari luar perusahaan akan mempengaruhi pengungkapan yang dilakukan oleh perusahaan. Hal tersebut diartikan bahwa semakin banyak pihak yang berkepentingan untuk mendapatkan informasi mengenai perusahaan tersebut, maka semakin banyak rincian yang harus diungkapkan dan berarti pengungkapan perusahaan menjadi semakin luas.

Selain porsi kepemilikan publik, masyarakat tentu ingin mendapatkan informasi mengenai pimpinan perusahaan tersebut karena masyarakat akan menilai kinerja pimpinan (manajemen) perusahaan dan jumlah komisaris yang ada serta keefektifannya berdasarkan proporsi jumlahnya. Menurut Akhtaruddin, et al, (2009) dalam Wijayanti (2013 ) Jika nilai proporsi komisaris independen tinggi berkaitan dengan transparansi perusahaan dan bisa dinilai sejauh mana pengungkapan informasi yang telah dilakukan perusahaan. Dalam penelitian Barako (2007) dan Al Janadi (2013) dalam Wijayanti (2013) terbukti dimana proporsi komisaris independen berpengaruh terhadap pengungkapan sukarela yang dibuat oleh perusahaan.

Reputasi kantor akuntan publik yang memeriksa laporan keuangan perusahaan, berhubungan dengan pengungkapan sukarela karena dalam laporan keuangan mencerminkan tranparansi bagi pemeriksa laporan keuangan tersebut. Menurut Benardi dkk. (2009) dalam Adhi (2012) Laporan keuangan tahunan yang sudah di audit akan membatu para investor untuk menentukan keputusan bisnisnya, karena itu auditor memiliki peran yang sangat penting. Kualitas auditor membantu meningkatkan strategi pelaporan perusahaan secara keseluruhan.

Hal ini sesuai dengan Benardi dkk. (2009) dalam Adhi (2012) yang mengatakan bahwa kualitas sumber daya manusia dan teknologi yang dimiliki oleh para kantor akuntan publik mempengaruhi kualitas atau hasil kerja auditnya. Jika kantor akuntan publik berukuran kecil memiliki sumber dan teknologi yang terbatas sedangkan kantor akuntan publik berukuran besar akan memiliki kualitas yang lebih baik.

Ukuran kantor akuntan publik dibagi menjadi dua kategori, yaitu kantor akuntan publik yang memiliki lingkup dunia atau global (Big Four) dan kantor akuntan publik dengan lingkup domestik atau non Big Four.

Kantor akuntan publik Big Four terdiri dari Deloitte Touche Tohmatsu, PWC (Price Waterhouse Coopers), Ernst \& Young, dan KPMG (Klynveld Peat Main Goerdeler). Asumsi dari pengelompokkan kantor akuntan publik adalah kantor akuntan publik Big Four memiliki kosistensi, kualitas dan profesionalitas karena itu dapat mendorong perusahaan untuk melakukan pengungkapan yang lebih luas dibandingkan dengan kantor akuntan publik kecil. Sedangkan kantor akuntan publik kecil diasumsikan memiliki kosistensi, kualitas dan profesionalitas 
yang belum cukup, sehingga cenderungan akan berusaha mengkuti kebutuhan kliennya.

Beberapa penelitian mengenai pengungkapan sukarela telah dilakukan, diantaranya oleh Wardani (2013) dengan hasil penelitian dimana variabel porsi kepemilikan publik tidak berpengaruh terhadap pengungkapan sukarela, Wijayanti (2013) dengan hasil penelitian variabel Proporsi dewan komisaris independen tidak berpengaruh signifikan terhadap pengungkapan sukarela dan Fitriana (2014) dengan hasil penelitian untuk variabel ukuran kantor akuntan publik berpengaruh positif terhadap pengungkapan sukarela.

Dan pada penelitian ini, dilakukan penelitian pada perusahaan Property dan Real Estate yang terdaftar di Bursa Efek Indonesia. Alasan memilih perusahaan Property dan Real Estate karena di Indonesia ini, prospek dalam hal Property dan Real Estate sangat baik, karena perkembangannya sangat pesat misal pada pembangunan jalan, gedung, perkantoran dan lainnya sehingga itu semua menjadi peluang bagi investor untuk menanamkan dananya ke dalam Perusahaan Property dan Real Estate. Pemilihan tahun 2014 - 2016 karena membutuhakan data yang dapat mewakili perkembangan terbaru dari laporan keuangan perusahaan dan diharapkan penelitian dapat lebih relevan.

Berdasarkan latar belakang permasalah di atas maka penelitian mengenai pengungkapan sukarela mengambil faktor-faktor diantaranya porsi kepemilikan publik, proporsi dewan komisaris independen dan ukuran KAP. Tujuan dari penelitian ini adalah untuk mengetahui pengaruh dari porsi kepemilikan publik, proporsi dewan komisaris independen dan ukuran KAP terhadap pengungkapan sukarela

\section{TINJAUAN PUSTAKA}

\section{Teori Agensi (Agency Theory)}

Menurut Jensen dan Meckling (1976) dalam Fitriana (2014) terjadi hubungan keagenan (agency relationship) , manajemen perusahaan sebagai agen dan pemegang saham (principal). Ada kontrak diantara mereka, dimana satu orang atau lebih (principal) memberikan perintah kepada agen untuk melakukan suatu jasa tertentu demi kepentingan para principal, namun agen diberikan keweangan untuk membuat keputusan yang terbaik bagi principal.

Menurut Wijayanti (2013) antara agen dan prinsipal memiliki tujuan yang berbeda, dimana agen akan mendapatkan kompensasi keuangan dan kepuasan dari keterlibatannya dalam hubungan keagenan contohnya mendapatkan waktu luang yang lebih, suasana kerja yang baik dan flesibel dalam jam kerja. Tujuan utama prinsipal adalah agar mendapatkan pengembalian keuntungan atau keuangan yang diperoleh dari investasi mereka pada sebuah perusahaan. Jika prinsipal tidak mendapatkan informasi yang cukup mengenai kinerja agen, prinsipal akan merasa tidak mendapatkan kepastian mengenai usaha yang telah dilakukan agen dalam memberikan kontribusi pada hasil akhir perusahaan. Hal ini akan dapat menimbulkan asimetri informasi atau dengan kata lain terjadi informasi yang tidak seimbang antara pemegang saham dengan agen 
Menurut Adhi (2012) : Para pemegang saham membutuhkan alat kontrol untuk dapat mengurangi terjadinya asimetri informasi karena asimetri informasi dapat menjadi sangat merugikan bagi pihak para pemegang saham.

Pengungkapan sukarela yang lebih lengkap pada laporan tahunan perusahaan, dapat digunakan oleh stakeholders sebagai alat kontrol agar risiko asimetri informasi dapat dikurangi. Karena informasi yang diberikan kepada stakeholders lebih transparan

Menurut Scott (2000) dalam Wicaksono (2011), asimetri informasi terdiri dari:

\section{Adverse Selection}

Pegawai atau orang yang bekerja didalam perusahaan, termasuk para manajer pastinya lebih banyak mengetahui keadaan dan prospek masa depan perusahaan dibandingkan dengan pihak luar. Jika ada fakta yang kemungkinan dapat mempengaruhi keputusan para pemegang saham, biasanya tidak akan disampaikan informasi tersebut dan ditahan oleh manajer dan pihak dalam perusahaan.

2. Moral Hazard

Para manajer dan manajemen memiliki informasi yang lebih akurat dan lebih lengkap dibandingkan oleh para pemegang saham, namun kegiatan para manajer tidak seluruhnya dapat diketahui oleh para pemegang saham ataupun para kreditor. Karena itu manajer dapat melakukan tindakan melanggar kontrak, meskipun secara norma maupun etika mungkin tidak layak dilakukan. Manajer selalu ingin memberikan laporan kondisi perusahaan yang baik kepada para pemegang saham.

\section{Porsi Kepemilikan Publik}

Porsi kepemilikan publik diukur dengan rasio jumlah saham yang dimiliki masyarakat (publik) terhadap total saham. Dimana publik adalah pihak perseorangan atau individu diluar manajemen dan tidak mempunyai hubungan istimewa dengan perusahaan (Wardani, 2013). Perusahaan go public sendiri artinya sahamnya bebas dimiliki oleh masyarakat.

Sedangkan jumlah saham yang ditawarkan kepada publik menunjukkan besarnya private information yang harus dibagikan oleh manajer kepada masyarakat (publik). Private information adalah informasi yang hanya diketahui oleh manajer, diantaranya : pengukuran kinerja perusahaan, perencanaan bonus, dan lainnya. Dengan adanya kepemilikan publik mengharuskan para manajer memberikan informasi secara berkala sebagai bentuk pertanggung jawabannya. (Purwaty,2016).

Perusahaan yang memiliki proporsi kepemilikan publik besar akan berakibat perusahaan harus memberikan pengungkapan informasi yang lebih banyak. (Puwandari ,2012).

Jensen dan Meckling (1976) dalam Anisa (2011) : pihak yang berkepentingan meningkat seiring dengan jumlah pemegang saham publik. Akibatnya mengharuskan manajemen melakukan pengungkapan yang lebih detail. Dampak lainnya adalah meningkatnya biaya keagenan. 


\section{Proporsi Dewan Komisaris Independen}

Proporsi dewan komisaris independen diukur dengan menjumlah semua anggota dewan komisaris independen yang berasal dari luar perusahaan dibagi dengan total dewan komisaris pada perusahaan (Afnan,2014). Jika dalam laporan keuangan sebuah perusahaan tidak dicantumkan jumlah anggota dewan komisaris independen, maka komisaris independen dihitung sebanyak 1 orang, sesuai dengan undang-undang perseroan terbatas No. 40 tahun 2007

Dengan adanya komisaris independen, diharapkan dapat melakukan tugas pengawasan dan juga memberikan nasihat kepada direksi secara efektif dan dapat memberikan nilai tambah bagi perusahaan (Riniati,2015). Semua pihak yang berkepentingan terutama stakeholder akan mendapatkan manfaat yang sangat besar karena adanya komisaris independen (Safietrie,2017). Perusahaan akan lebih banyak melakukan pengungkapan sukarela, tingkat pengawasan manajerial akan semakin efektif jika semakin besar proporsi komisaris independen yang ada di perusahan tersebut.

\section{Ukuran KAP}

Menurut Mulyadi, 2011:52, Kantor Akuntan Publik adalah sebuah organisasi akuntan publik yang telah memperoleh izin sesuai dengan undangundang di bidang pemberian jasa professional dalam praktik akuntan publik (Sukrisno, 2016:44).

Pekerjaan auditor diantaranya adalah melakukan audit dengan tujuan untuk memberikan pendapat atas kewajaran laporan keuangan, sesuai dengan prinsipprinsip akuntansi yang berlaku umum.

Setiap KAP tentunya menginginkan memiliki auditor yang dapat bekerja dengan baik dalam melakukan audit. Karena seorang auditor dituntut untuk professional dalam melaksanakan tugasnya agar dapat menumbuhkan kepercayaan dari klien dan para pengguna laporan keuangan. Untuk bisa mempertahankan kepercayaan klien, auditor dituntut untuk memiliki kinerja yang baik. Kualitas yang baik akan tercapai kinerja yang baik juga.

Menurut Yuliana dan Aloysia (2004) dalam Fiatmoko (2015), Kantor Akuntan Publik yang masuk dalam kategori the big four yaitu :

1. Kantor Akuntan Publik Price Waterhouse Cooper, bekerja sama dengan KAP Tanudiredja, Wibisana \& Rekan.

2. Kantor Akuntan Publik KPMG (Klynfeld Peat Marwick Goedelar), bekerja sama dengan KAP Sidharta dan Widjaja.

3. Kantor Akuntan Publik Ernst and Young, bekerja sama dengan KAP Purwantono, Suherman dan Surja.

4. Kantor Akuntan Publik Delloite Tauche Thamatshu, bekerja sama dengan KAP Osman Bing Satrio.

KAP besar (big four accounting firms) diasumsikan akan melakukan audit dengan lebih berkualitas jika dibandingkan dengan KAP kecil (non big four accounting firms). KAP besar biasanya akan lebih berhati-hati dalam menyatakan opini dan tidak tergantung pada beberapa klien saja karena mereka memiliki sumber daya yang banyak dan kepercayaan atau reputasi yang lebih baik jika dibandingkan dengan KAP kecil (Putri, 2012) 
Pada penelitian ini, ukuran Kantor Akuntan Publik diukur dengan variabel dummy, dimana nilai 1 untuk KAP big four dan nilai 0 untuk KAP non big four (Pardosi, 2012).

\section{Pengukapan Sukarela}

Disclosure artinya penyajian laporan keuangan yang memberikan informasi secara jelas dan lengkap, serta memberikan gambaran kejadian ekonomi yang mempengaruhi hasil operasi suatu perusahaan secara akurat. arti kata disclosure adalah tidak menutupi atau tidak menyembunyikan.

Menurut Meek et al. (1995) dalam Wulandari (2015) manajemen dapat memilih informasi apa saja yang akan diungkapkan atau disajikan secara relevan dan berguna dalam pengambilan keputusan bagi pihak yang memerlukan. Karena itu pengungkapan sukarela di sebut juga pengungkapan bebas.

Menurut (Meek.Roberts dan Gray,1995) dalam Anastasia (2016) Pengungkapan sukarela adalah pengungkapan butir-butir yang dilakukan oleh sebuah entitas dan tanpa peraturan yang berlaku. Dengan memberikan pengungkapan sukarela dapat meningkatkan krebilitas perusahaan. Namun dalam memberikan pengungkapan sukarela, perusahaan harus lebih berhati-hati karena menurut Beattie dan Smith (2010) dalam Melyana (2015) perusahaan diharapkan tidak memberikan informasi yang dapat membahayakan posisi persaingan perusahaan, menyebarluaskan dan mengumpulan informasi memerlukan biaya yang cukup besar dan menimbulkan pengawasan yang tidak diinginkan dari pihak stakeholders dan badan pengaturan

\section{METODOLOGI PENELITIAN}

\section{Jenis Penelitian}

Jenis penelitian dalam penelitian ini adalah penelitian kuantitatif. Menurut Sugiyono (2016:8), metode penelitian kuantitatif untuk meneliti pada populasi atau sampel tertentu dengan tujuan untuk menguji hipotesis yang telah ditetapkan. Data yang digunakan berupa laporan keuangan tahunan perusahaan yang di ambil dari situs resmi BEI yaitu www.idx.com .

\section{Populasi dan Sample}

Populasi yang digunakan dalam penelitian ini adalah perusahaan property dan real estate di Bursa Efek Indonesia (BEI) tahun 2014 - 2016.

Pengambilan sampel dalam penelitian ini dilakukan dengan menggunakan metode purposive sampling. Kriteria penentuan sampel dalam penelitian ini adalah sebagai berikut:

1. Perusahaan property dan real estate yang sudah go public atau terdaftar di Bursa Efek Indonesia (BEI) selama periode 2014-2016.

2. Perusahaan memiliki laporan tahunan (annual report) periode 2014-2016.

3. Perusahaan menerbitkan laporan keuangan tahunan yang dinyatakan dalam rupiah $(\mathrm{Rp})$.

4. Perusahaan mencantumkan jumlah porsi kepemilikan publik. 
5. Perusahaan mencantumkan jumlah anggota dewan komisaris independen.

6. Adanya laporan independen auditor.

\section{HASIL PENELITIAN DAN PEMBAHASAN}

Tabel 4.1

Hasil Analisis Regresi Linear Berganda

\begin{tabular}{|l|l|l|l|l|l|}
\hline \multicolumn{1}{|c|}{ Variabel } & $\begin{array}{l}\text { Koefesien } \\
\text { Regresi (B) }\end{array}$ & Standart Eror & t-hitung & Sig. & Keterangan \\
\hline Konstanta & 0,421 & 0,046 & 9,129 & 0,000 & \\
\hline $\begin{array}{l}\text { Porsi Kepemilikan } \\
\text { Publik }\end{array}$ & 0,122 & 0,061 & 1,995 & 0,050 & H1 Diterima \\
\hline $\begin{array}{l}\text { Proporsi Dewan } \\
\text { Komisaris } \\
\text { Independen }\end{array}$ & 0,033 & 0,122 & 0,267 & 0,790 & H2 Ditolak \\
\hline Ukuran KAP & 0,094 & 0,028 & 3,415 & 0,001 & H1 Diterima \\
\hline $\mathrm{R}^{2}$ & $=0,156$ & & & \\
\hline Adj. $\mathrm{R}^{2}$ & $=0,123$ & & & \\
\hline F-Statistik & $=4,740$, sig. $=$ \\
\hline $\mathrm{N}$ & 0,004 & & \\
\hline
\end{tabular}

Hasil dari tabel diatas, Hipotesis H1 diterima, dimana porsi kepemilikan publik berpengaruh secara signifikan terhadap pengungkapan sukarela dengan nilai signifikan 0,050. Hipotesis $\mathrm{H} 2$ ditolak, dimana proporsi dewan komisaris independen tidak berpengaruh signifikan terhadap pengungkapan sukarela dengan nilai signifikan 0,790 . Hipotesis H3 diterima , dimana ukuran KAP berpengaruh signifikan terhadap pengungkapan sukarela dengan nilai signifikansi 0,001

Tabel 4.2

\section{Hasil Uji Statistik F}

ANOVA $^{\mathrm{a}}$

\begin{tabular}{|ll|l|l|l|l|l|}
\hline \multicolumn{2}{|c|}{ Model } & Sum of Squares & Df & Mean Square & F & Sig. \\
\hline \multirow{4}{*}{1} & Regression &, 161 & 3 &, 054 & 4,740 &, $004^{\mathrm{b}}$ \\
& Residual &, 872 & 77 &, 011 & & \\
& Total & 1,033 & 80 & & & \\
\hline
\end{tabular}

Sumber : Data diolah dengan SPSS 22

Untuk membuktikan hipotesis keempat, pada tabel 4.2 hasil analisis regresi ganda, diperoleh nilai $\mathrm{F}$ hitung sebesar 4,740 dengan nilai signifikansi sebesar 0,004 , Nilai ini lebih besar dari $\mathrm{F}$ tabel $(4,740>3,11)$ dan nilai sig. $\mathrm{F}$ $0,004<0,05$ 
Maka hipotesis H4 diterima, dimana Porsi Kepemilikan Publik, Proporsi Dewan Komisaris Independen, dan Ukuran KAP memiliki pengaruh secara bersama-sama (simultan) terhadap Pengungkapan Sukarela pada perusahaan perusahaan property dan real estate yang terdaftar di Bursa Efek Indonesia tahun 2014-2016

Tabel 4.3

Hasil uji Koefisien Determinasi

\begin{tabular}{|l|r|r|r|r|}
\hline Model & \multicolumn{1}{|c|}{$\mathrm{R}$} & R Square & \multicolumn{1}{|c|}{$\begin{array}{c}\text { Adjusted R } \\
\text { Square }\end{array}$} & \multicolumn{2}{|c|}{ Std. Error of the Estimate } \\
\hline 1 &, $395^{\mathrm{a}}$ &, 156 &, 123 &, 10644 \\
\hline
\end{tabular}

Hasil dari analisis regresi berganda dengan menggunakan program SPSS 22 diperoleh nilai koefisien regresi Porsi kepemilikan publik sebesar 0,122, nilai koefisien regresi Proporsi dewan komisaris independen sebesar 0,033, nilai koefisien regresi Ukuran KAP sebesar 0,094, dan nilai konstanta sebesar 0,421. Maka persamaan regresi berganda yang dihasilkan adalah $\mathrm{Y}=0,421+0,122 \mathrm{PKP}$ $+0,033 \mathrm{KOM}+0,094 \mathrm{KAP}$

\section{KESIMPULAN}

Hasil dari analisis regresi berganda menunjukkan bahwa porsi kepemilikan publik dan ukuran KAP berpengaruh signifikan terhadap pengungkapan sukarela, sedangkan proporsi dewan komisaris tidak berpengaruh signifikan terhadap pengungkapan sukarela. Jadi dari hasil analisis yang telah dilakukan ,hipotesis $\mathrm{H} 1$ dan $\mathrm{H} 3$ dapat diterima sedangkan hipotesis $\mathrm{H} 2$ tidak dapat diterima atau ditolak.

Dan hasil dari hipotesis H4 terbukti bahwa Porsi kepemilikan publik, proporsi dewan komisaris independen dan ukuran KAP secara bersama-sama atau simultan berpengaruh terhadap pengungkapan sukarela

\section{DAFTAR PUSTAKA}

Adhika Nirmalasari Ginting (2012). Analisis Faktor Yang Mempengaruhi Tingkat Pengungkapan Sukarela Dalam Laporan Tahunan Perusahaan Manufaktur di Indonesia. Fakultas Ekonomi, Universitas Indonesia

Akhamad Afnan (2014). Pengaruh Ukuran Dewan Komisaris, Proporsi Komisaris Independen Terhadap Kinerja Keuangan Dengan Manajemen Laba Sebagai Variabel Intervening. Fakultas Ekonomika Dan Bisnis, Universitas Diponegoro 
Anita Yolanda Suta (2012). Analisis Faktor-Faktor Yang Mempengaruhi Luas Pengungkapan Informasi Sukarela Laporan Tahunan. Fakultas Ekonomika dan Bisnis, Universitas Diponegoro

Arizal Latif Fiatmoko (2015). Pengaruh Ukuran perusahaan, Ukuran KAP, Laba/Rugi Operasi dan Opini Audit Terhadap Audit Delay Pada Perusahaan Perbankan yang terdaftar di BEI Tahun 2010-2012

Arum Purwandari (2012). Pengaruh Profitabilitas, Leverage, Struktur Kepemilikan Dan Status Perusahaan Terhadap Pengungkapan Laporan Keuangan Pada Perusahaan Manufaktur Indonesia. Fakultas Ekonomika Dan Bisnis. Universitas Diponegoro

Bintang Bagus Wicaksono (2011). Pengaruh Karakteristik Perusahaan Terhadap Luas Pengungkapan Sukarela Pada Laporan Keuangan. Fakultas Ekonomi, Universitas Diponegoro

Berty Wahyu Putri (2012). Penentuan Kualitas Audit Berdasarkan Ukuran KAP Dan Biaya Audit. Jurnal Ilmiah Mahasiswa Akuntansi Vol.1 No.4 Hal:6064

Budi Susilo (2010). Kepemilikan Manajerial, Proporsi Dewan Komisaris Independen, Jumlah Komite Audit, Dan Keahlian Komite Audit Terhadap Manajemen Laba. Fakultas Ekonomi Dan Bisnis, Universitas Islam Negeri Syarif Hidayatullah

Dadan Ramdhani. (2011). International Accounting. Cetakan Kesatu, Yogyakarta: Markumi Lintas Pustaka.

Delvinur (2015). Pengaruh Leverage, Likuiditas dan Proporsi Kepemilikan Saham Publik Terhadap Luas Pengungkapan Sukarela Dalam Laporan Tahunan. Fakultas Ekonomi, Universitas Negeri Padang

Diajeng Chrisnoventie (2012). Pengaruh Ukuran KAP dan Spesialis Industri Terhadap Kualitas Audit : Tingkat Risiko Litigasi Perusahaan Sebagai Variabel Moderasi. (Studi Empiris pada Perusahaan Manufaktur di BEI Tahun 2008-2010). Fakultas Ekonomika Dan Bisnis, Universitas Diponegoro

Dian Safietrie (2017). Pengaruh Dewan Komisaris Independen Terhadap Profitabilitas Bank Syariah Dengan Non Performing Financing (NPF) Sebagai Variabel Intervening. Fakultas Ekonomi Dan Bisnis Islam, Institut Agama Islam Negeri Salatiga

Duroriyatul Aulya, Sutono, dan Sri Harjanto (2015). Pengaruh Profitabilitas, Likuiditas, Kepemilikan Saham Publik dan Umur Listing Terhadap Voluntary Disclosure Pada Perusahaan Manufaktur di Indonesia. STIE Dharmaputra

Eska Almuntaha, dkk.(2016). Apakah Reputasi Akuntan Publik Mempengaruhi Kestabilan Harga Saham. Simposium Nasional Akuntansi XIX, Lampung

Finda Dwi Hanifah (2017). Pengaruh Corporate Governance, Kondisi Financial Distress, Dan Proprietary Cost Terhadap Luas Pengungkapan Sukarela Laporan Tahunan Perusahaan. Fakultas Ekonomi, Universitas Muhammadiyah Yogyakarta

Gerhat Pardosi (2012). Analisis Pengaruh Opini Auditor, Audit Report Lag dan Kantor Akuntan Publik Terhadap Harga Saham pada Perusahaan 
Manufaktur yang Terdaftar di Bursa Efek Indonesia Tahun 2008-2010. Fakultas Ekonomi, Universitas Sumatera Utara

Imam Ghozali. (2014). Ekonometrika Teori, Konsep dan Aplikasi dengan IBM SPSS 22. Semarang : Badan Penerbit - Undip.

Kuslinah Riniati (2015). Pengaruh Komisaris Independen Dan Komite Audit Terhadap Kinerja Perusahaan. Fakultas Ekonomi, Universitas Negeri Yogyakarta

Muhammad Hidayat. (2017). Faktor-Faktor Yang Mempengaruhi Pengungkapan Sukarela Pada Laporan Tahunan Sektor Perbankan Di Bursa Efek Indonesia. Fakultas Ekonomi, Universitas Riau Kepulauan, Indonesia

Mulyadi. Auditing. (2011). Cetakan Kedelapan, Jakarta : Salemba Empat.

Muthia Ramadani Sadono. (2016). Pengaruh Proporsi Dewan Komisaris Independen, Ukuran Komite Audit Dan Ukuran Perusahaan Terhadap Siklus Konversi Kas (Cash Convertion Cycle). Fakultas Ekonomi Dan Bisnis, Universitas Islam Syarif Hidayatullah.

Nancy Yunita (2012). Pengaruh Corporate Governance Terhadap Voluntary Disclosure dan Biaya Hutang. Jurnal Ilmiah Mahasiswa Akuntansi

Noor Laila Fitriana (2014). Faktor-Faktor Yang Mempengaruhi Luas Pengungkapan Sukarela Dalam Annual Report. Fakultas Ekonomika dan Bisnis, Universitas Diponegoro

Nurseto Adhi. (2012). Pengaruh Karakteristik PerusahaanTerhadap Luas Pengungkapan Sukarela Dan Implikasinya Terhadap Asimetri Informasi. Fakultas Ekonomika dan Bisnis Universitas Diponegoro

Rany Purwaty (2016). Ukuran Perusahaan, Leverage, Porsi Kepemilikan Publik, ROI Dan Ukuran KAP Terhadap Luas Pengungkapan Sukarela. Jurusan Akuntansi, Sekolah Tinggi Ilmu Ekonomi Perbanas Surabaya

Rr. Puruwita Wardani. (2013). Faktor-Faktor yang Mempengaruhi Luas Pengungkapan Sukarela. Fakultas Bisnis, Universitas Katolik Widya Mandala Surabaya

Rusti Melyana (2015). Pengaruh Pengungkapan Sukarela Terhadap Nilai Perusahaaan. Fakultas Ekonomika Dan Bisnis, Universitas Diponegoro

Sandy Wijayanti (2013). Pengaruh Ukuran Perusahaan, Leverage dan Profitabilitas terhadap Luas Pengungkapan Sukarela. Fakultas Ekonomi, Universitas Jember

Singgih Santoso. Menguasai SPSS 22 From Basic to Expert Skill. Cetakan Pertama, Jakarta : PT. Elex Media Komputindo, 2015

Sugiyono. (2016). Metode Penelitian Kuantitatif Kualitatif Dan R\&D. Cetakan Ke-23, Bandung : Alfabeta.

Sukrisno Agoes Auditing. (2016). Petunjuk Praktis Pemeriksaan Akuntan oleh Kantor Akuntan Publik", Cetakan Keempat.Jakarta : Salemba Empat.

Tulus Prijanto dan Yuni Pristiwati Noer Widianingsih (2012). Faktor-Faktor Yang Mempengaruhi Voluntary Disclosure Perusahaan Go Public. Jurnal Akuntansi dan Sistem Teknologi Informasi, Sekolah Tinggi Ilmu Ekonomi Swastamandiri Surakarta

Wahyuni Wijayanti. (2013). Analisis Pengaruh Corporate Governance Dan Karakteristik Perusahaan Terhadap Pengungkapan Sukarela (Voluntary 
Disclosure) Dalam Lalporan Tahunan. Fakultas Ekonomi Dan Bisnis, Universitas Islam Negeri Syarif Hidayatullah Jakarta

Wilujeng Dwi Anisa. (2011). Pengaruh Likuiditas, Profitabilitas, Ukuran Perusahaan, Dan Kepemilikan Saham Publik Terhadap Pengungkapan Laporan Tahunan. Fakultas Ekonomi, Universitas Negeri Semarang

Yesi Wulandari. (2015). Analisis Faktor-Faktor Yang Mempengaruhi Luas Pengungkapan Informasi Sukarela Pada Laporan Keuangan Tahunan. Fakultas Ekonomi Dan Bisnis, Universitas Diponegoro

Yona Luksandy. (2016). Pengaruh Mekanisme Corporate Governance dan Proprietary Cost Terhadap Luas Pengungkapan Sukarela Serta Implikasinya Terhadap Nilai Perusahaan. Universitas Muhammadiyah Yogyakarta.

Yosi Anastasia. (2016). Pengaruh Pengungkapan Sukarela, Beta Saham Dan Ukuran Perusahaan Terhadap Cost of Equity Capita Pada Perusahaan Barang Konsumsi di Indonesia. Fakultas Ekonomi dan Bisnis, Universitas Lampung. 